\begin{tabular}{|c|l|}
\hline Title & Spinal cord compression by multistrand cables after solid posterior atl antoaxial fusion. Report of three cases. \\
\hline Author(s) & Sudo, Hideki; A bumi, K.; Ito, M.; Kotani, Y. \\
\hline Citation & Journal Of Neurosurgery, 97(3 Suppl), 359-361 \\
\hline Issue Date & 2002-10 \\
\hline Doc URL & http:/hdl.handle.net/2115/14598 \\
\hline Rights & $\begin{array}{l}\text { The final version of the paper was published in Journal Of Neurosurgery, vol. 97-3. For reuse of any of the materials, } \\
\text { including editorial copy, figures, or tables please contact the Journal of Neurosurgery at jneuro@ virginia.edu }\end{array}$ \\
\hline Type & article \\
\hline File Information & JN2002-97-3.pdf \\
\hline
\end{tabular}

Instructions for use 


\title{
Spinal Cord Compression by Multistrand Cables after Solid Posterior Atlantoaxial Fusion
}

\author{
Hideki Sudo,MD \\ Kuniyoshi Abumi,MD \\ Manabu Ito,MD \\ Yoshihisa Kotani,MD \\ Akio Minami,MD.
}

Department of Orthopaedic Surgery, Hokkaido University Graduate School of Medicine, Sapporo, Japan.

Correspondence;

\author{
Kuniyoshi Abumi,MD \\ Department of Orthopaedic Surgery \\ Hokkaido University Graduate School of Medicine \\ North-15, West-7, Kita-ku \\ Sapporo, Hokkaido 060-8638, Japan \\ Phone:+81-11-706-5934 FAX:+81-11-706-6054 \\ E-mail: abumi@med.hokudai.ac.jp
}

\section{Key words:}

multistrand cable, spinal cord compression, atlantoaxial fusion 


\section{Abstract}

The sublaminar wiring procedure has been commonly used for stabilizing the atlantoaxial complex. Multistrand braided cables started to be used in early 1990s. Previous biomechanical studies demonstrated that these cables were superior to monofilament wires in terms of their flexibility, mechanical strength and fatigue characteristics. This is the first clinical report describing delayed spinal cord compression by multistrand cables after the completion of rigid spinal arthrodesis in the upper cervical spine.

Three patients underwent posterior atlantoaxial fusion by two sublaminar multistrand cables. At postoperative 15 to 48 months, they suffered from numbness in the upper and lower extremities and gait disturbance. Plain radiographs and CT myelogram showed spinal cord compression by the sublaminar cables, although arthrodesis was complete and physiological alignment was maintained at the fused segment. The radiographs taken immediately after surgery showed that the initial cable placement had been properly performed. The shape of the cable at the initial surgery was oval and then gradually changed its shape into circle. The anterior arc of a circular cable did lead to the spinal cord compression.

Considering the mechanism of this late complication, a cable tends to spring open due to its high flexibility and turns to be a circular shape even after the complete arthrodesis. When applying multistrand cables for intersegmental fixation at the atlantoaxial complex, delayed complications related to bowing of the cables is a possibility.

\section{Key words:}

multistrand cable, spinal cord compression, atlantoaxial fusion 


\section{Introduction}

Sublaminar wiring procedure including Brooks' method ${ }^{3}$ has been commonly used for stabilization of the atlantoaxial instability. Several complications related to the use of monofilament wires have been reported. Reported complications include epidural hemorrhage, $^{10,16}$ dural contusion $^{8}$ and cerebrospinal fluid leakage. ${ }^{12}$ Wire breakage and its spinal cord compression was also reported by Fraser et al. ${ }^{6}$

Many spine surgeons started to use multistrand braided cables in early 1990s. Previous biomechanical studies demonstrated that these cables were superior to monofilament stainless wires in terms of their flexibility, mechanical strength and fatigue characteristics. ${ }^{4,5,9,14,15}$ Songer et al. reported good clinical results of patients treated with multistrand braided cables. ${ }^{14}$ According to their results, there were no complications associated with the cables including cable breakage or loosening. Up to the present, there has been only one complication report related to the breakage of the cables. ${ }^{2}$

This is the first clinical report to describe delayed spinal cord compression by multistrand cables after the complete posterior atlantoaxial arthrodesis. 


\section{Cases}

\section{Case 1.;}

A 65 year-old woman with a history of rheumatoid arthritis, atlantoaxial instability and subaxial lesion, had undergone posterior atlantoaxial fusion with two multistrand cables and laminoplasty from C3 to C7. Before the initial surgery, the patient had numbness in the bilateral upper and lower extremities and a disturbance of fine finger motion. Neurologic deficits were improved after surgery. Postoperative radiographs demonstrated that the initial wiring procedure was properly performed and the shape of the cable was oval (Figure1A).

At postoperative 4 years, the patient noted a gait disturbance characterized by spasticity in the lower extremities and recurrent numbness in the upper and lower extremities. A plain lateral cervical x-ray film showed anterior bowing of the cables causing spinal cord compression. The shape of the cable was a circle which was different from that at the initial surgery. Fusion was successful and grafted bone did not change in size (Figure1B). CT myelogram demonstrated circular sublaminar cables compressing the spinal cord at C1/2. Progression of subaxial lesion at C3/4 was also seen on the radiograph.

At the second surgery, cable removal, prophylactic posterior decompression, and posterior fusion were simultaneously done to treat future problems in subaxial lesion. At the time of the removal, the solid fusion mass was identified and the cables were embedded in the fusion mass. Great caution was taken to avoid the spring action of the cables which might cause additional spinal cord injury. We utilized a high-speed burr to remove the fusion mass around the cable so that one edge of the cable could be cut closest to the spinal canal and the other could be pulled in horizontal direction to minimize the spring action of the cable. Patient's neurological conditions were improved after surgery. 


\section{Case 2;}

A 70 year-old man was involved in a car accident and sustained fractures of the cranial and the facial bone, and dislocation of the left hip joint. At the time of car accident, the patient did not undergo any surgical treatment. At 28 years later, the patient developed neck pain, gait disturbance characterized by spasticity in the lower extremites and bladder and bowel disturbance. He was diagnosed as a traumatic atlantoaxial sublaxation and underwent posterior atlantoaxial fusion in combination of two sublaminar multistrand cables and Magerl procedure. ${ }^{11}$ The procedure was properly performed (Figure2A).

At 33 months postoperatively, he experienced a gait disturbance. Neurologic examination showed definite cervical myelopathy. Myelography and following CT revealed the spinal cord compression by the circular cables which had been placed in oval shape at the initial surgery (Figure2B,2C). The arthrodesis appeared to be solid and the physiological alignment was preserved at the fused segment. At the time of cable removal, the solid bony fusion mass was identified. The cables were removed with the same manner as performed in the case1. The myelopathy symptoms recovered after the removal.

\section{Case 3;}

A 36 years-old man sustained a traumatic atlantoaxial subluxation due to a motor vehicle accident. The patient underwent posterior spinal fusion from C1 to C2 with two multistrand cables at a local hospital. At 15 months postoperatively, he experienced numbness in the left upper extremity and a gait disturbance. X-rays showed shape change of the cables after the initial surgery and the anterior arc of the circular cables eventually caused spinal cord compression (Figure3). The cervical myelopathy improved after removal of the cables. 


\section{Discussion}

Posterior wiring for the upper cervical spine has been a standard treatment for a wide range of pathologic conditions, such as rheumatoid arthritis and traumatic ligamentous instabilities. However, there have been complications including spinal cord injury caused by the wire passage or its breakage. ${ }^{7}$ Fraser et al. suggested that wire breakage in early postoperative period is caused by tightening wires beyond their permissible mechanical strength or with improper tightening techniques. ${ }^{6}$ They also pointed out that delayed failures of wires were derived from repeated mechanical stress on the wires due to incomplete bony fusion., ${ }^{1,6}$

Songer et al. firstly described the clinical application of multistrand cables for spinal surgeries in 1991. ${ }^{14}$ The advantages of this cable were their flexibility and secure passage beneath the lamina. They also reported no breakage or loosening of the cables because of their reliable mechanical stiffness.

There has been one case report describing cable fracture and subsequent neurological injury. ${ }^{2}$ The present article firstly reported 3 cases of delayed complication related to the cables after solid fusion. The technique of placing cables during the surgery was not problematic. Considering the mechanism of the cable bowing, the multistrand cable tends to spring open due to its high flexibility and turns to be a circular shape even after complete arthrodesis. In our 3 patients, the cables were embedded in the solid fusion mass. Remodeling of the fusion mass may have occurred by the continuous mechanical stress from the cables on the grafted bone. Such phenomenon is well described in clinical orthodontics as a bone resorption at the site of compression force for long periods of time. ${ }^{13}$

We do not have an accurate grasp of the rate of such complication. However, every multistrand cable does not necessarily lead to the aforementioned complication. We did not experience such complication of the cable when the cable was applied for monosegmental fixation in scoliosis 
surgery. We presume that the morphological change of a cable may occur when a cable is applied for intersegmental fixation. Although the initial shape of the cable over 2 laminae is oval immediately after surgery, it tends to be a circular shape due to its mechanical characteristics. Over years after surgery, the cable will dig a ditch into the grafted bone and its circular arc will cause spinal cord compression.

In conclusion, when applying multistrand cables for intersegmental fixation at the atlantoaxial complex, delayed complications related to bowing of the cables is a possibility. 


\section{References}

1. Bernard TN, Johnston CE, Roberts JM, Burke SW. Late complications due to wire breakage in segmental instrumentation. Report of two cases. J Bone Joint Surg 1983;65-A:1339-45.

2. Blacklock JB. Fracture of sublaminar stainless steel cable in the upper cervical spine with neurological injury. Case report. J Neurosurg 1994;81:932-933.

3. Brooks AL, Jenkins EB. Atlanto-axial arthrodesis by the wedge compression method. J Bone Joint Surg 1978;60-A:279-284.

4. Dickman CA, Papadopoulos SM, Crawford NR, Brantley AG, Gealer RL. Comparative mechanical properties of spinal cable and wire fixation systems. Spine 1997;22:596-604.

5. Dickman CA, Sonntag VK. Wire fixation of the cervical spine: Biomechanical principles and surgical techniques. BNI Quartely 1993;9:2-16.

6. Fraser AB, Sen C, Casden AM, Catalano PJ, Post KD. Cervical transdural intramedullary migration of a sublaminar wire. Spine 1994;19:456-459.

7. Geremia GK, Kim KS, Cerullo L, Calenoff L. Complication of sublaminar wiring. Surg Neurol 1985;23:629-34.

8. Herring JA, Wenger DR. Segmental spinal instrumentation.A preliminary report of 40 consecutive cases. Spine 1982;7:285-98.

9. Huhn SL, Wolf AL, Ecklund J. Posterior spinal osteosynthesis for cervical fracture/dislocation using a flexible multistrand cable system: Technical note. Neurosurgery $1991 ; 29: 943-6$.

10. Johnston CE, Happel LT, Norris R, Burke SW, King AG, Roberts JM. Delayed paraplegia complicating sublaminar segmental spinal instrumentation. J Bone Joint Surg 1986;68-A:556-63. 
11. Magerl F, Seemann P-S. Stable posterior fusion of the atlas and axis by transarticular screw fixation. In: Kehr P, Werdner PA, eds. Cervical Spine I. New York: Springer-Verlag, $1987 ; 322-7$.

12. Renshaw TS, Solga PM, Drennon JC, Donskoy E. Studies of an L-rod sublaminar wire spinal fusion. J Pediatr Orthop 1991;11:226-9.

13. Retain K. Tissue behavior during orthodontic tooth movement. Am J Orthod 1960;46:881-900.

14. Songer MN, Spencer DL, Meyer PR, Jayaraman G. The use of sublaminar cables to replace Luque wires. Spine 1991;16S:S418-21.

15. Weis JC, Cunningham BW, Kanayama M, Parker L, McAfee PC. In Vitro Biomechanical comparison of multistrand cables with conventional cervical stabilization. Spine 1996;21:2108-2114.

16. Wilber RG, Thompson GH, Shaffer JW, Brown RH, Nash CL. Postoperative neurological deficits in segmental spinal instrumentation. A study using spinal cord monitoring. J Bone Joint Surg 1984;66-A:1178-87. 


\section{Capture of Figures}

Figure 1.

Case 1: A, Plain X-ray of initial posterior atlantoaxial fusion with two multistrand cables and a subaxial laminnoplasty from C3 to C7 is shown. Wiring procedure was properly performed. B, Plain radiograph at postoperative 5 years shows anterior bowing of the cables penetrating the spinal canal. The shape of the cable is a circular shape which is different from that at the initial surgery (arrows). However, the previous fusion was successful and grafted bone does not change in size throughout after surgery.

\section{Figure 2.}

Case2: A, A plain X-ray of initial posterior atlantoaxial fusion in combination of two sublaminar multistrand cables and Magerl procedure is shown. The procedure was properly performed (Figure2A). B, Lateral X-ray shows the circular cables penetrating the spinal canal. Arthrodesis appears to be solid and the physiological alignment is preserved at the fused segment. C, CT myelogram shows spinal cord compression by the cables passing away from the ventral laminar surface (arrows).

\section{Figure 3.}

Case3: X-rays shows that the anterior arc of the circular cables causes spinal cord compression after changing its shape into circle. 
i

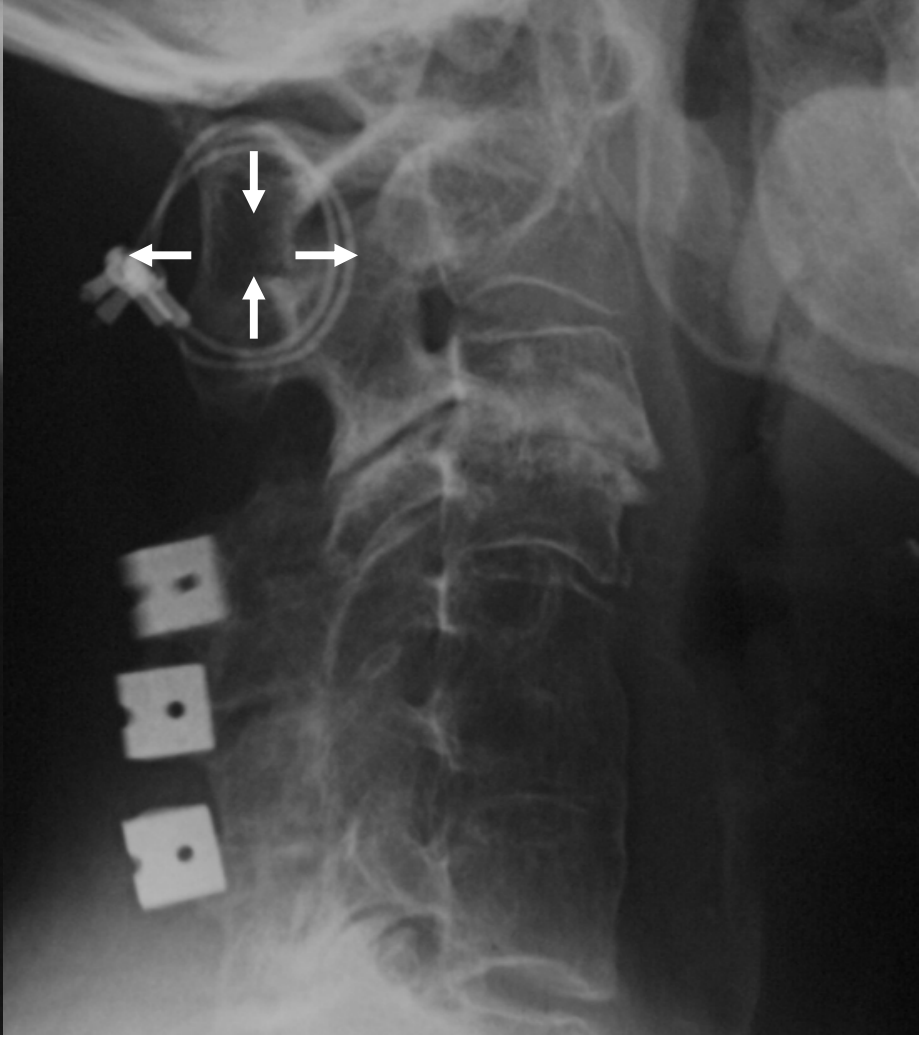




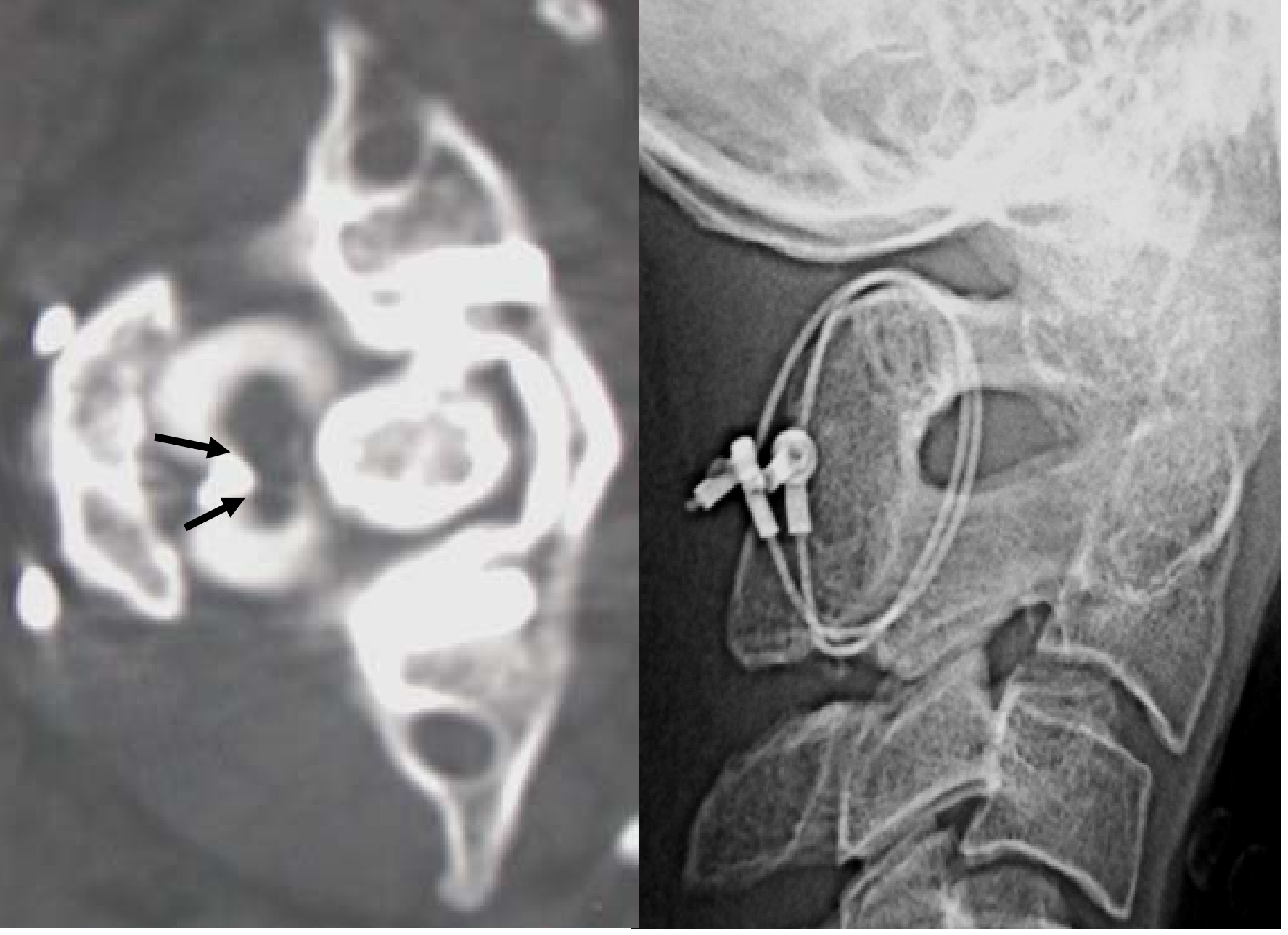




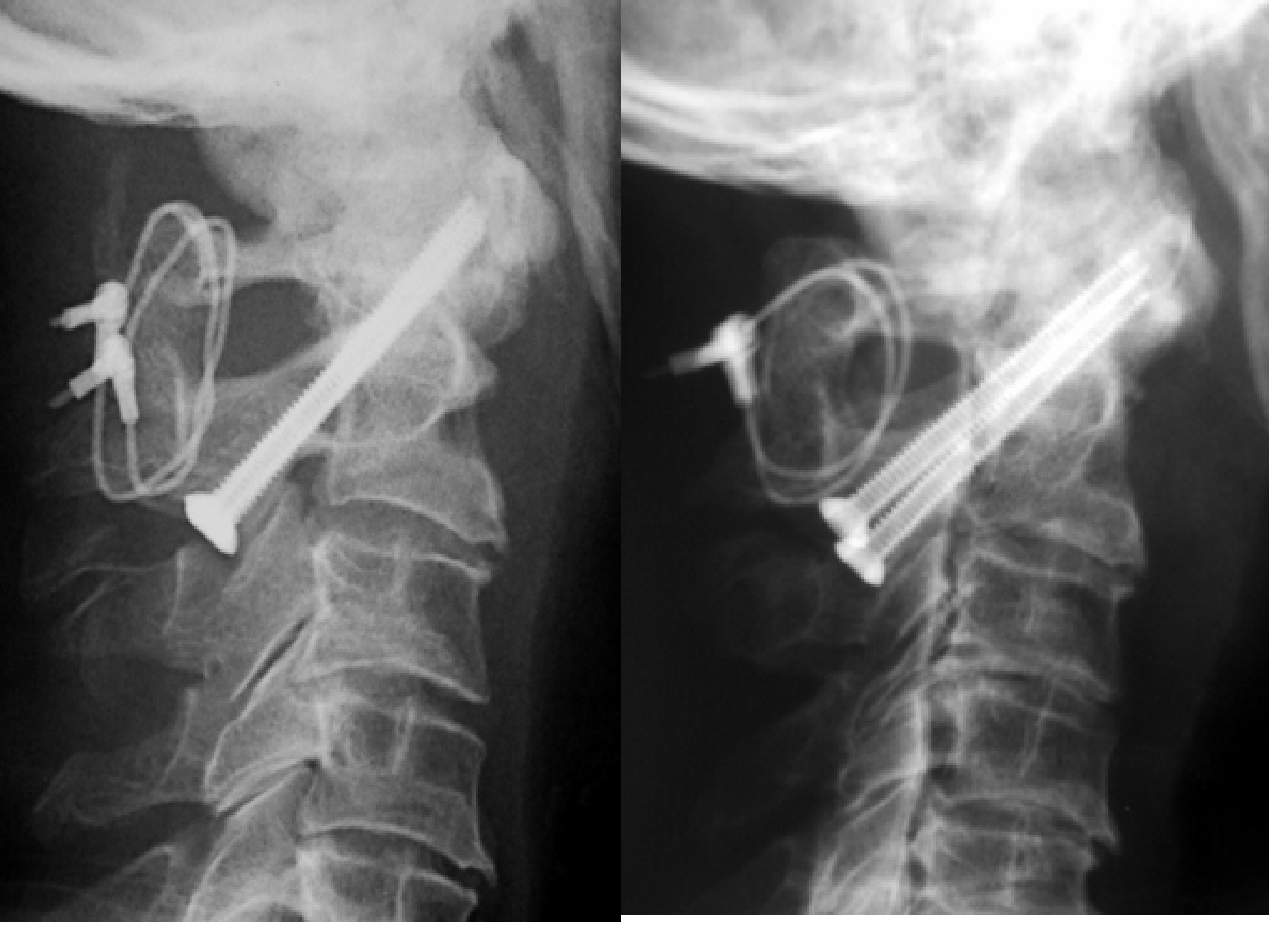

